\title{
ACUTE LYMPHOBLASTIC LEUKEMIA; CHROMOSOMAL ABNORMALITIES IN CHILDHOOD REPORTING AT A TERTIARY CARE HOSPITAL OF SINDH
}

1. Department of Pathology, Isra University, Hyderabad

2. Department of Veterinary Pathology,

Sindh Agriculture University, Tandojam

3. Department of Pathology, Al-Tibri Medical College, Karachi

4. Department of Pathology, Liaquat University of Medical and Health Sciences, Jamshoro.

Correspondence Address: Dr. Amin Fahim, M.Phil Assistant Professor

Deptt: of Pathology Al-Tibri Medical College Old Thana, Gadap Town Malir, Karachi

draminfahim@gmail.com

Article received on: 02/12/2015

Accepted for publication: 08/01/2016

Received after proof reading: 10/03/2016

\section{Dr. Ghulam Shah Nizzamani', Zaheer Ahmed Nizamani², Dr. Amin Fahim ${ }^{3}$, Dr. Ikram Uddin Ujjan ${ }^{4}$}

\begin{abstract}
Objectives: The aim of the present study is to evaluate the frequency of chromosomal abnormalities in childhood acute lymphoblastic leukemia at a tertiary care hospital of Sindh. Study design: Observation study. Place of study: Isra University Hospital, Hyderabad and Oncology Unit Liaquat University of Medical and Health Sciences, Jamshoro. Duration of study: From January 2014 to March 2015. Materials and Methods: Cytogenetic analysis was conducted on peripheral blood and bone marrow samples of 100 diagnosed cases of acute lymphoblastic leukemia (ALL). Peripheral blood and bone marrow samples were collected and putted into sodium heparinized bottles. Cytogenetic analysis was performed by karyotyping according to the ISCN guidelines for human cytogenetic nomenclature using cytovision-+ system for image analysis. Data was analyzed on statistic 8.1 USA and expressed as means, percentage and chi-square with P-value of $\leq 0.05$ being defined significant. Results: Chromosomal abnormalities were found in $53 \%$ of the ALL cases. Numerical abnormalities were found in $71 \%$ whereas $35 \%$ cases showed structural abnormalities. $29 \%$ cases of ALL showed diploidy and aneuploidy was found in $69 \%$ of cases and $2 \%$ cases were unknown. Highest number of patients $51 \%$ showed hyperploidy followed by $12 \%$ cases of hypoploidy and $6 \%$ showed pseudoploidy. Chromosomal translocations $\mathrm{t}(9 ; 22)$ (q34; q11) and $\mathrm{t}(8 ; 22)$ (q24; q11) were noted in $6 \%$ each and $\mathrm{t}(8 ; 14)$ (q22; q32) were seen in $5 \%$ of the cases of childhood ALL. Conclusion: The present study reports chromosomal abnormalities in $53 \%$ of cases. Numerical abnormalities were found in $71 \%$ whereas $35 \%$ cases showed structural abnormalities.
\end{abstract}

Key words: $\quad$ Childhood Acute lymphoblastic leukemia, Chromosomal, Numerical and structural abnormalities

Article Citation: Nizzamani GS, Nizamani ZA, Fahim A, Ujjan IU. Acute lymphoblastic leukemia; chromosomal abnormalities in childhood reporting at a tertiary care hospital of Sindh. Professional Med J 2016;23(3):312-316. DOI: 10.17957/ TPMJ/16.3199

\section{INTRODUCTION}

Neoplastic proliferation with differentiation of lymphoid progenitors seen on bone marrow characterizes acute lymphoblastic leukemia (ALL). Various classifications of ALL have been documented based on prognostic significance and their biological behavior. Immature lymphoid cell lines at different stages of maturation may show cell cycle arrest resulting in the malignant transformation. ${ }^{1}$

In Pakistan insufficient data is available regarding the incidence and chromosomal abnormalities of ALL. ${ }^{2}$ The most common age involvement of ALL is below the age of fifteen years. In a retrospective study in Karachi conducted by Yasmeen et al revealed $32 \%$ frequency regarding the cases of childhood ALL. ${ }^{2}$

Various abnormalities involving the chromosomal deletions and translocations have been reported in the literature. Many of these often show dysregulation of the gene expression. The karyotypic changes in children with ALL have been documented to affect $80 \%$ children ${ }^{3}$ whereas in adults it is reported around $79 \%$ cases with ALL. ${ }^{1,4}$

The normal diploid $2 \mathrm{n}$ number of chromosomes may show either decrease or increase in patients with ALL showing aneuploidy. A significant variation in the childhood ALL and adults show hyperploidy with more than $2 \mathrm{n}$ chromosomes 
in about $30 \%$ and $5 \%$ cases respectively. ${ }^{5,6}$ Trisomies may involve the specific chromosomal involvement. $^{7}$

In addition decreased chromosomal number less than diploid $2 \mathrm{n}$ may be the second common ALL related abnormality in childhood. However the incidence is somewhat lower affecting about $6 \%$ cases of ALL. ${ }^{8}$ The most common chromosomal defect is hypoploidy with 45 chromosomes. ${ }^{8,9}$ Comparatively it has poor prognosis when compared with hyperploidy. ${ }^{8-10}$ The gold standard method of choice for the diagnosis of cytogenetic abnormalities is with conventional chromosomal analysis in patients with suspected leukemia. ${ }^{1,10}$

A search of literature shows a few reported studies from Pakistan in general and Sindh in particular, hence more studies are needed to explore chromosomal abnormalities in acute lymphoblastic leukemia in our population.

\section{MATERIAL AND METHODS}

A Cross sectional study was conducted at Isra University Hospital, Hyderabad and Liaquat University of Medical and Health Sciences, Jamshoro from January 2014 to March 2015. One hundred diagnosed cases of ALL were selected according to inclusion and exclusion criteria through non-probability purposive sampling. Diagnosed cases of ALL were included, while patients of other types of acute leukemia, lymphoma, and multiple myeloma were excluded from study.

Informed written consent was taken from parents/ guardians. The study was approved by ethics committee of institute. Peripheral blood and bone marrow samples were drawn from the diagnosed cases of acute lymphoblastic leukemia and putted into sodium heparinized bottle for cytogenetic analysis. CBC was performed on haematology analyzer sysmex 1000i. Cytogenetic analyses were performed from samples heparinized tube and cultured (RPMI medium) and stimulated with mitogen phytohaemeagglutinin (PHA) \& incubated at 37 degree centigrade. Incubate in $0.075 \mathrm{M} \mathrm{KCl}$ (Hypotonic solution in water bath).
Fixed examined on slide. Karyotype analysis were performed and classified according to the International System for Human Cytogenetic Nomenclature (ISCN) using cytovision system for image analysis.

The statistical analysis of data was done through SPSS version 21.0 and graphical representation with Microsoft excel. The student's t test was applied for the continuous variables whereas $\square 2$ test for the categorical variables. The $p$-value of $\leq$ 0.05 is defined as significant.

\section{RESULTS}

Mean age of the subjects was $7.5 \pm 3.2$ years. The most frequent age groups were 5-10 years and $<5$ years noted in $59(59 \%)$ and $35(35 \%)$ respectively. The gender wise distribution of the ALL cases showed $57 \%$ and $43 \%$ cases of males and females respectively with $\mathrm{p}$-value $=0.09$. The ratio of male to female ratio was found to be 1.32:1. Hemoglobin concentration of $<08 \mathrm{~g} /$ dl in $9 \%$ and $8-10 \mathrm{~g} / \mathrm{dl}$ in $49 \%$ more than $10 \mathrm{~g} /$ dl in $42 \%$ of the cases. In approximately $33 \%$ of the ALL patients showed more than 5million/ $\mu \mathrm{L}$ count of red blood cells whereas maximum number $61 \%$ patients with ALL showed red blood cell counts of $2-5$ million $/ \mu \mathrm{L}$ followed by only $6 \%$ cases showing less than 2 million/ $\mu \mathrm{L}$ RBC count with $p$-value $=0.001$. The maximum number $59 \%$ patients of ALL showed more than $100,000 / \mu \mathrm{L}$ white blood cell count followed by $17 \%$ and $15 \%$ ALL cases showing 10,000-50,000 and 50,000100,000 white blood cell count. Only $9 \%$ of ALL cases showed less than 10,000 white blood cell with $\mathrm{p}$-value $=0.0001$.

Chromosomal abnormalities were noted in $53 \%$ patients while numerical and structural abnormalities were found in $71 \%$ and $35 \%$ cases respectively. Diploidy and aneuploidy were noted in $29 \%$ and $69 \%$ of cases while $2 \%$ showed unknown. 51 cases of hyperploidy, $6 \%$ were found to have hypoploidy $12 \%$ had pseudoploidy (Table-I \& Figure-I). 


\begin{tabular}{|l|c|c|c|}
\hline & No. of Pt. & $\%$ & p-value \\
\hline Hyperploidy & 51 & 51 & \\
\hline Hypoploidy & 6 & 6 & \multirow{2}{*}{0.001} \\
\hline Pseudoploidy & 12 & 12 & \\
\hline Unknown & 2 & 2 & \\
\hline
\end{tabular}

Table-I. Chromosomal Numerical abnormalities

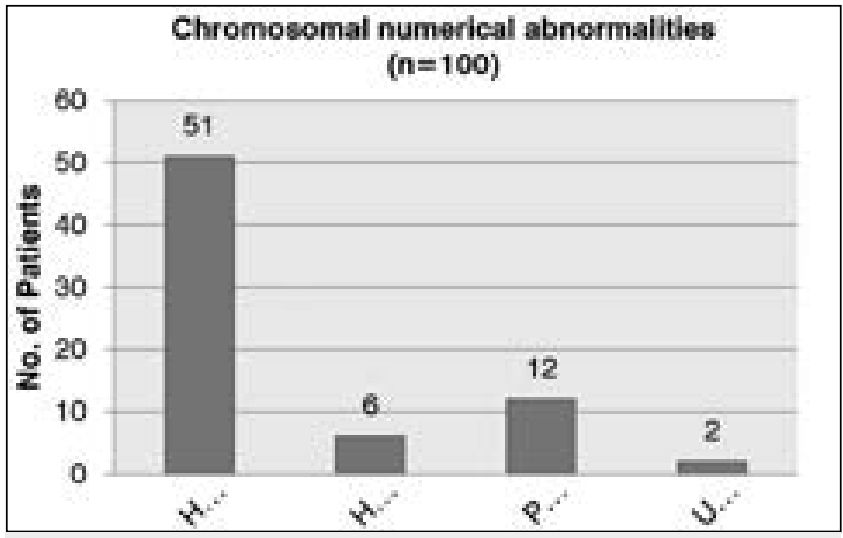

Figure-1. Numerical abnormalities in study population

Chromosomal translocations found in the present study are summarized in table-I. Chromosomal translocations $\mathrm{t}(9 ; 22)(\mathrm{q} 343 ; \mathrm{q} 11)$ and $\mathrm{t}(8 ; 22)$ (q24; q11) were noted $6 \%$ in each. $2^{\text {nd }}$ common Chromosomal translocation were $\mathrm{t}(8 ; 14)$ (q24;q32) in $5 \%$ cases. However unknown translocations were seen in $13 \%$ of the cases (Table-II \& Fig-2).

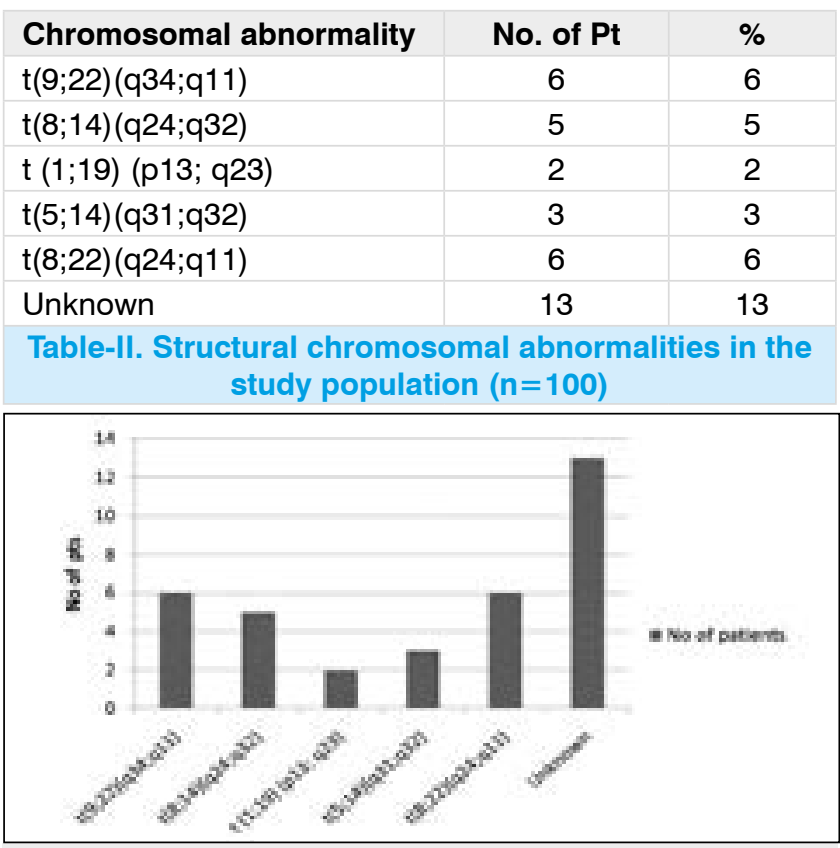

Figure-2. Chromosomal structural abnormalities

\section{DISCUSSION}

A search of literature shows that a few studies have been conducted on the childhood ALL in Pakistan. Present study is the first study conducted at our Tertiary Care Hospital. The mean age of ALL patients in present study was noted as $7.5 \pm 3.2$ years while most frequent age groups were $5-10$ years and $<5$ years noted in $59(59 \%)$ and $35(35 \%)$ respectively. The mean age of cases of present study is consistent with a study ${ }^{11}$ from Karachi which reported a mean age of $7 \pm 4.4$ years.

In the present study the gender wise distribution of the ALL cases showed $57 \%$ and $43 \%$ cases of males and females respectively with $p$-value $=0.09$. The ratio of male to female ratio was found to be 1.32:1. The finding in accordance with previous studies ${ }^{11,12}$ which reported a male to female ratio of $1.8: 1$ and $1.7: 1$ in Pakistani children respectively. The findings suggest a male predominance in childhood ALL.

Chromosomal abnormalities were noted in 53\%, numerical and structural abnormalities were found in $71 \%$ and $35 \%$ respectively. Diploidy, aneuploidy and unknown were noted in $29 \%, 69 \%$ and $2 \%$ of cases respectively. Numerical abnormalities were found, hyperploidy in $51 \%$ cases, hypoploidy in $6 \%$ of cases, pseudoploidy in $12 \%$ of cases. Frequency of chromosomal abnormalities of present is consistent with previous study ${ }^{11}$ which had reported a frequency of $48.8 \%$ which is in accordance with the findings of the present study.

Another previous study ${ }^{13}$ showed chromosomal abnormalities in $64 \%$ of cases. The numerical abnormalities involved $53 \%$ of the cases followed by $26 \%$ cases revealing structural abnormalities. Moreover both the structural as well as numerical abnormalities were found in about $21 \%$ cases. The findings are consistent with present study.

The finding of hyperploidy is consistent with a previous study ${ }^{14}$, but Shaikh et al ${ }^{11}$ reported lower (13.4\%) frequency of hyperploidy which is not in agreement with present study. One reason of low frequency in Shaikh et al ${ }^{11}$ was the obsolete 
technique they used, while present study used more sophisticated conventional Keryotyping. The differences might had occurred because of this reason. Nonetheless the sample size of present is larger as compared to previous study from Karachi.

Another previous study ${ }^{15}$ reported cytogenetic abnormalities being present in $3 / 4$ of the patients with only $22 \%$ patients showing normal diploid $2 n$ karyotype. In another study by Pui et al ${ }^{14}$ revealed structural abnormalities in approximately $62 \%$ of the cases with $26 \%$ cases showing hyperdiploidy. The findings of present study are parallel to above and other previous studies. ${ }^{15-20}$

In the present study Philadelphia $t(9 ; 22)$ ( $q 34$; q11.2) was noted in $6 \%$ of ALL cases which is comparable to $3-5 \%$ of pediatric ALL reported previously. ${ }^{21}$ However, a previous study ${ }^{11}$ has reported Philadelphia chromosome in $7.08 \%$ of cases.

The lymphoid $\mathrm{B}$ or $\mathrm{T}$ cell immunophenotype results are not presented in the current study however, the prognostic importance of ALL with cytogenetic abnormalities can be of valuable importance shown in the present study.

It is thus concluded that hyperploidy with greater than normal diploid $2 \mathrm{n}$ chromosomal number having good prognosis is an important finding. Frequency of chromosomal aberrations like Philadelphia chromosome having poor prognosis and hypoploidy are consistent with findings of world literature.

The inclusion and exclusion criteria with prospective design of the present study have strengthened the objective goals. However the sample size in the present study blocks the findings of the present study to be generalized for the whole population.

\section{CONCLUSION}

Chromosomal abnormalities were found in $53 \%$ of the ALL cases. Numerical abnormalities were found in $71 \%$ whereas $35 \%$ cases showed structural abnormalities. $29 \%$ cases of ALL showed diploidy and aneuploidy was found in $69 \%$ of cases and $2 \%$ cases were unknown. Highest number of patients 51\% showed hyperploidy followed by $12 \%$ cases of hypoploidy and 6\% showed pseudoploidy. Chromosomal translocations t $(9 ; 22)$ (q34; q11) and $\mathrm{t}(8 ; 22)$ ( $\mathrm{q} 24 ; \mathrm{q} 11)$ were noted $6 \%$ in each whereas $(8 ; 14)(q 22 ; q 32)$ in $5 \%$ of the cases of childhood ALL. Overall, this study provides further understanding of cytogenetic and molecular abnormalities in ALL cases.

Copyright (C) 08 Jan, 2016.

\section{REFERENCES}

1. Robbinson HM. Acquired abnormalities of chromosome 21 in acute lymphoblastic leukemia. (Thesis). Faculty of Science, School of Medicine, University of Southampton 2008: 23-41.

2. Yasmeen N, Ashraf S. Childhood Acute Lymphoblastic Leukaemia; Epidemiology and Clinico-pathological Features. J Pak Med Assoc 2009; 59(3): 151-4.

3. Harrison CJ. The genetics of childhood acute lymphoblastic leukemia. Baillieres Best Prac Res Clin Haematol 2000; 13:427-39.

4. Moorman AV, Harrison CJ, Buck GA, Richards SM, Secker-Walker LM, Martineau M, at al. Karyotype is an independent prognostic factor in adult acute lymphoblastic leukemia (ALL): analysis of cytogenetic data from patients treated on the Medical Research Council (MRC) UKALLXII/Eastern Cooperative Oncology Group (ECOG) 2993 trial. Blood 2007; 109:3189-97.

5. Secker-Walker LM, Lawler SD, Hardisty RM. Implications of chromosomal findings in acute lymphoblastic leukemia at diagnosis. British Medical Journal 1978; 2:1529-30.

6. Moorman AV, Richards SM, Martineau M, Cheung KL, Robinson HM, Jalali GR, et al. Outcome heterogeneity in Childhood high-hyperdiploid acute lymphoblastic leukemia. Blood 2003; 102:2756- 62.

7. Moorman AV, Clark R, Farrell DM, Hawkins JM, Martineau M, Secker-Walker LM. Probes for hidden hyperdiploidy in acute lymphoblastic leukemia. Genes Chromosomes and Cancer 1996; 16:40-5.

8. Harrison CJ, Moorman AV, Broadfield ZJ, Cheung KL, Harris RL, Reza JG. Three distinct subgroups of hypodiploidy in acute lymphoblastic leukemia. $\mathrm{Br} \mathrm{J}$ Haematol 2004; 125:552-9. 
9. Raimondi SC, Zhou Y, Mathew S, Shurtleff SA, Sandlund JT, Rivera GK. Reassessment of the prognostic significance of hypodiploidy in pediatric patients with acute lymphoblastic leukemia. Cancer 2003; 98:2715-22.

10. Mitelman F, Johansson B, Mertens F. The impact of translocations and gene fusions on cancer causation. Nat Rev Cancer 2007; 7:233-45.

11. Shaikh MS, Ali SS, Khurshid M, Fadoo Z. Chromosomal Abnormalities in Pakistani Children with Acute Lymphoblastic Leukemia. Asian Pac J Canc Prev 2014; 15: 907-9.

12. Yasmeen N, Ashraf S. Childhood acute lymphoblastic leukemia; epidemiology and clinicopathological features. J Pak Med Assoc 2009; 59: 105-3.

13. GilEA, Lajus TBP, de Moura TMO, Freire JM, daFernandes ALA, Leao GDR, et al. Banding cytogenetic analysis in pediatric patients with acute lymphoblastic leukemia (ALL) in a Brazilian population. Mol Cytogen 2013; 6:37.

14. Pui $\mathrm{CH}$, Crist WM. Cytogenetic abnormalities in childhood acute lymphoblastic leukemia correlate with clinical features and treatment outcome. Leukemia lymphoma 1992; 7:259-274.

15. Perez-Vera P, Mujica-Sanchez M, Carnevale A, RiveraLuna R, Paredes R, Martinez-Frias S. Cytogenetics in acute lymphoblastic leukemia in Mexican children: an institutional experience. Arch Med Res 2001;
32:202-7.

16. Perkins D, Brennan S, Carstairs K, Bailey D, Pantalony $D$, Poon A, Fernandes B, et al. Regional cancer cytogenetics: a report on 1,143 diagnostic cases. Cancer Genet Cytogenet 1997; 96:64-80.

17. Amare P, Gladstone B, Varghese C, Pai S, Advani $\mathrm{S}$. Clinical significance of cytogenetic findings at diagnosis and in remission in childhood and adult acute lymphoblastic leukemia: experience from India. Cancer Genet Cytogenet 1999; 110:44-53.

18. Caspersson T, Zech L, Johansson C, Modest EJ. Identification of human chromosomes by DNAbinding fluorescent agents. Chromosoma 1970; 30:215-27.

19. Garcia DR, Bhatt S, Manvelyan M, de Souza MT, Binato R, Aguiar TF, et al. An unusual T-cell childhood acute lymphoblastic leukemia harboring a yet unreported near-tetraploid karyotype. Mol Cytogenet 2011; 4:20.

20. Al-Achkar W, Aljapawe A, Othman MAK, Wafa A. A de novo acute myeloid leukemia (AML-M4) case with a complex karyotype and yet unreported breakpoints. Mol Cytogenet 2013; 6:18.

21. Schultz KR, Bowman WP, Aledo A. Improved early event-free survival with imatinib in Philadelphia chromosome-positive acute lymphoblastic leukemia: a children's oncology group study. J Clin Oncol 2009; 27: 5175-81.

\begin{tabular}{|c|c|c|c|}
\hline \multicolumn{3}{|c}{ AUTHORSHIP AND CONTRIBUTION DECLARATION } \\
\hline Sr. \# & \multicolumn{1}{|c|}{ Author-s Full Name } & \multicolumn{1}{c|}{ Contribution to the paper } & Author=s Signature \\
\hline 1 & Dr. Ghulam Shah Nizzamani & $\begin{array}{l}\text { Conception \& Design } \\
\text { Writing the article Final } \\
\text { approval of the article } \\
\text { Abtaimed funding Analysis } \\
\text { and interpretation, Critical } \\
\text { revision of the article } \\
\text { Data collection, Critical } \\
\text { revision of the article } \\
\text { Writing the article, Data } \\
\text { collection, Statistical } \\
\text { analysis }\end{array}$ \\
\hline 3 & Zaheer Ahmed Nizamani & Dr. Amin Fahim & Dr. Ikram Uddin Ujjan \\
\hline
\end{tabular}

